$\begin{array}{|ll|}\text { Received } & : \text { 12 Juni } 2019 \\ \text { Revised } & : \text { 18 Juni } 2019 \\ \text { Accepted } & : \text { 5 September } 2019 \\ \text { Published } & : \text { 27 Desember } 2019\end{array}$

\title{
Needs Analysis for Developing of Bahasa Indonesia's Placement Test at SPK School in Tangerang
}

\author{
Yoanita Muliawan ${ }^{1, \mathrm{a})}$ \\ 1 \\ Universitas Pelita Harapan, Tangerang, Indonesia \\ E-mail: ${ }^{a)}$ ym80098@ student.uph.edu
}

\begin{abstract}
This preliminary study aims to confirm the need to develop a bahasa Indonesia placement test for an International Baccalaureate (IB)-based SPK school in Tangerang. The researcher uses the needs analysis method by collecting quantitative and qualitative fata from the entire audiences through interviews, surveys, documentation and field observations. From this study it was concluded that the development of a better Indonesian placement test is needed in terms of test questions, contents and thoroughness of the rubric, and procedures in marking. It is the researcher's expectation that the results of this study will be of benefit to other IB-based schools in need for a more accurate Indonesian placement test.
\end{abstract}

Keywords: placement test, Indonesian language, IB

\begin{abstract}
Abstrak
Penelitian ini adalah penelitian pendahuluan yang bertujuan untuk mengonfirmasi kebutuhan pengembangan tes penempatan bahasa Indonesia yang dipakai di sebuah sekolah SPK berbasis International Baccalaureate (IB) di Tangerang. Peneliti memakai metodeanalisakebutuhandengancaramengumpulkan data kuantitatif dan kualitatif dari seluruh audiens melalui wawancara, survei, dokumentasi, dan observasi lapangan. Dari penelitian ini, disimpulkan perlunya pengembangan tes penempatan bahasa Indonesia yang lebih baik dalam hal materi soal, isi dan kelengkapan rubrik, serta prosedur dalam melakukan penilaian. Hasil dari penelitian ini diharapkan dapat membantu sekolahsekolah berbasis IB yang juga membutuhkan tes penempatan bahasa Indonesia yang lebih akurat.
\end{abstract}

Kata kunci: tes penempatan, bahasa Indonesia, IB 


\section{PENDAHULUAN}

Analisis kebutuhan pengembangan tes penempatan kelas Bahasa Indonesia adalah bagian dari studi awal yang dilakukan oleh penulis dalam upaya meningkatkan keefektifan tes penempatan kelas Bahasa Indonesia yang dipakai di sebuah sekolah SPK bersertifikasi International Baccalaureate (IB). Sekolah ini terdiri dari SD, SMP, sampai SMA dengan siswa berlatar belakang multi-nasional.

McKay (2006) mengatakan bahwa penilaian untuk tujuan penempatan melibatkan taruhan yang tinggi, "when the placement decision is fixed and children are wrongly placed, then this can have a major impact on children's lives." Tes penempatan yang selama ini diberikan kepada murid yang mendaftar disinyalir belum dapat memberikan hasil yang cukup akurat sehingga berdampak pada efektivitas pembelajaran dan performa akademik siswa. Hasil penempatan yang tidak akurat juga berpengaruh pada pembagian kelas pada awal tahun akademik. Kesalahan pembagian kelas berdampak pada tingginya frekuensi perpindahan murid dari satu kelas ke kelas yang lain dan juga kebutuhan penambahan kelas. Seringkali penambahan kelas sudah tidak mungkin dilakukan ketika tahun akademik sudah berjalan, sehingga perpindahan tidak memungkinkan untuk terjadi.

Berangkat dari masukan guru Bahasa Indonesia di sekolah yang diteliti, penulis mengambil asumsi awal bahwa permasalahan penempatan ini berhubungan dengan materi tes penempatan dan guru/staf yang mewawancarai/menilai tes murid (Sudaryanto, Soeparno, \& Ferawati, 2018). Untuk mengonfirmasi kebutuhan tersebut, penulis melakukan studi awal dengan menggunakan analisis kebutuhan untuk mengembangkan sebuah tes penempatan kelas Bahasa Indonesia dengan tingkat akurasi yang lebih baik dan mudah digunakan oleh calon siswa dan guru/staf yang terlibat.

\section{METODE PENELITIAN}

Analisis kebutuhan adalah analisis yang dilakukan untuk mengidentifikasi kesenjangan antara harapan dan kenyataan, dan lebih dari itu memberikan petunjuk mengenai arah dan skala penelitian. Hutchinsons dan Waters (dalam Ahmad, 2017) mengidentifikasi kebutuhan sebagai "necessities, lacks, and wants," yang artinya adalah apa yang seharusnya ada, apa yang kurang, dan apa yang menjadi kebutuhan. Dengan demikian, analisis kebutuhan harus dilakukan oleh penulis sebelum memulai penelitian dan pengembangan, untuk melihat apakah pengembangan produk adalah sesuatu yang dibutuhkan oleh sekolah tersebut, dan juga untuk melihat apakah waktu dan sumber daya memungkinkan untuk melaksanakan penelitian pengembangan produk yang berguna bagi sekolah. Dalam studi ini, penulis mengadaptasi langkah-langkah analisis kebutuhan McCawley (2004), yaitu menulis tujuan, memilih audiens, mengumpulkan data, memilih sampel audiens, memilih instrumen, menganalisis data, dan follow up.

Tujuan dari analisis kebutuhan adalah untuk melihat apakah ada kesenjangan antara hasil tes penempatan dan performansi siswa yang sesungguhnya, serta mengetahui penyebab kesenjangan tersebut. Penulis juga mempertimbangkan permintaan dari pihak sekolah agar tes penempatan dapat difasilitasi oleh staf non-guru tanpa memengaruhi hasil penilaian siswa.

Audiens adalah pihak-pihak yang nantinya akan mengambil tindakan berdasarkan analisis ini (Brown, 1995). Walaupun tes penempatan ini ditujukan untuk menempatkan siswa pada fase yang benar, kebutuhan akan pengembangan tes 
penempatan ini datang dari guru/staf. Guru dan staf dalam Departemen Bahasa Indonesia terlibat langsung dalam proses seleksi penempatan siswa baru berdasarkan hasil tes. Dengan demikian, dapat disimpulkan bahwa audiens dari penelitian ini adalah guru Departemen Bahasa Indonesia dan Departemen Penerimaan karena sifat dan ukuran target audiens cukup terbatas, yaitu hanya guru/staf yang terlibat langsung dalam pelaksanaan tes. Selanjutnya, data akan dikumpulkan dari seluruh audiens untuk memastikan bahwa data mewakili kebutuhan audiens. Peneliti melibatkan juga guru bidang studi lain dan staf yang diperbantukan untuk mewawancarai murid dalam pelaksanaan tes wicara.

\section{Pengumpulan Data}

Analisis kebutuhan ini melibatkan pengumpulan data kualitatif dan kuantitatif yang diperoleh dengan menggunakan beberapa instrumen: wawancara langsung, survei, observasi, dan dokumentasi hasil tes. Data-data yang diperoleh dapat bersifat subjektif maupun objektif. Penulis dapat mewawancarai audiens dan mengambil data dengan sepengetahuan dan persetujuan dari Kepala Bagian Administrasi. Semua nama responden atau pun data pribadi akan disamarkan atau ditulis dalam inisial untuk mempertahankan kerahasiaan data. Survei akan dilakukan kepada seluruh target audiens (delapan guru Bahasa Indonesia, dua guru bidang studi lain, dan satu orang staf) dan diberikan melalui surel. Wawancara dilakukan dengan tiga responden yang berkepentingan langsung dengan hasil tes yang diteliti, yaitu Kepala Bagian Administrasi Kelas 7-12, Kepala Bidang Penerimaan, dan Kepala Departemen Bahasa Indonesia di sekolah tersebut. Wawancara berisi sembilan pertanyaan dan dilakukan secara one on one.

Peneliti melakukan proses dokumentasi dengan mengumpulkan beberapa hal berikut.

1. Jadwal wawancara Tes Wicara berdasarkan kecocokan dengan jadwal mengajar guru

2. Hasil tes penempatan kelas untuk siswa baru di sekolah X tahun akademik 20192020 (diwakili oleh kelas 7 dan 8), dibandingkan dengan data fase murid terkini. Fase murid terkini adalah fase murid saat ini setelah disesuaikan dengan masukan guru atau rekomendasi dari konselor sekolah

Peneliti mengobservasi pelaksanaan wawancara murid, sampel soal dan rubrik dari Tes Wicara, Tes Membaca, serta Tes Menulis. Tes ini diberikan kepada semua calon siswa yang mendaftar ke sekolah ini. Akan tetapi, anak dari guru asing tidak melalui tes. Penempatan fase untuk anak guru asing berdasarkan pertimbangan nonformal sehingga secara otomatis masuk ke fase 1 jika tidak pernah belajar bahasa Indonesia. Anak guru asing yang sebelumnya pernah belajar bahasa Indonesia akan diwawancarai/dinilai secara singkat/nonformal sebelum ditempatkan ke fase tertentu.

\section{HASIL DAN PEMBAHASAN}

Hasil dan pembahasan yang dipaparkan akan disampaikan menjadi tiga bagian, yaitu (a) survei, (b) wawancara, dan (c) dokumentasi.

\section{Survei}

Data survei dari responden dikumpulkan dan ditampilkan dalam bentuk grafik 
sebagai berikut.

GRAFIK 1. Grafik Hasil Survei untuk Indikator Tes Wicara

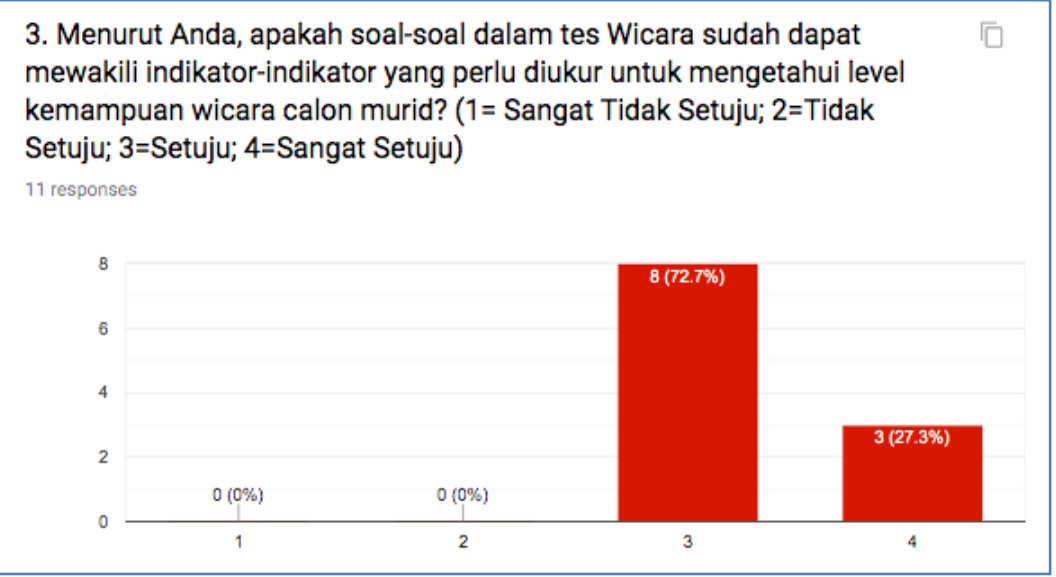

Berdasarkan hasil survei tersebut, semua responden menganggap bahwa soal-soal Tes Wicara sudah dapat mewakili indikator-indikator yang perlu diukur untuk mengetahui level kemampuan wicara calon murid.

Selanjutnya, penulis juga melakukan survei untuk menentukan apakah Tes Wicara juga sudah dapat menentukan fase belajar bahasa Indonesia untuk siswa. Hasil survei tersebut ditunjukkan pada grafik berikut.

GRAFIK 2. Grafik Hasil Survei untuk Fase Belajar Bahasa Indonesia Melalui Tes Wicara

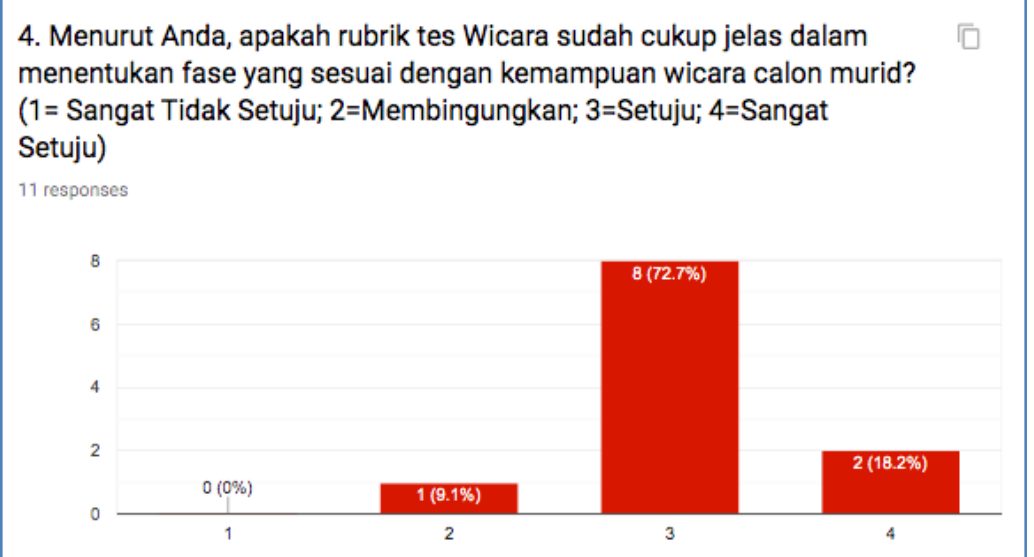

Berdasarkan hasil survei, mayoritas responden menyatakan bahwa rubrik Tes Wicara sudah cukup akurat dalam menentukan fase murid, dengan satu responden guru Bahasa Indonesia yang menyatakan bahwa rubrik Tes Wicara membingungkan.

Selain itu, penulis juga melaksanakan survei terkait kemudahan pemakaian Tes Wicara bagi penyelenggara tes yang tidak berlatar belakang guru Bahasa Indonesia. Hasil survei tersebut ditunjukkan pada grafik berikut. 


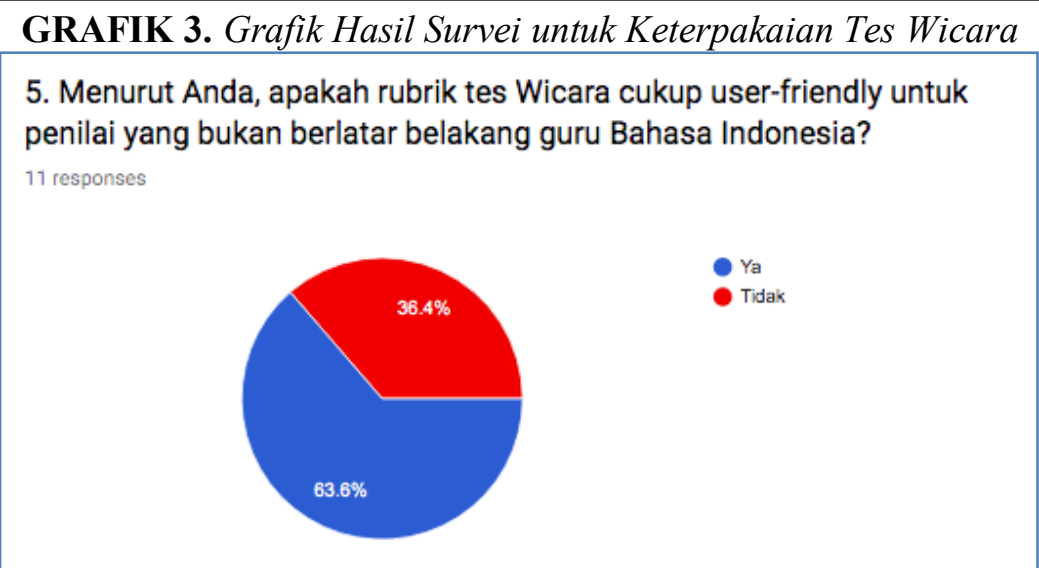

Berdasarkan hasil survei yang ditunjukkan pada grafik ketiga, lebih dari separuh responden menganggap bahwa rubrik Tes Wicara cukup ramah bagi pengguna, khususnya bagi penilai yang bukan guru Bahasa Indonesia.

Setelah melakukan survei untuk Tes Wicara, survei dilanjutkan pada Tes Membaca dan Tes Menulis. Pertanyaan survei yang pertama adalah tentang pengalaman guru dalam menilai paket Tes Membaca dan Tes Menulis. Berikut adalah grafik hasil survei.

GRAFIK 4. Grafik Hasil Survei untuk Penilaian terhadap Paket Tes Membaca dan Tes Menulis

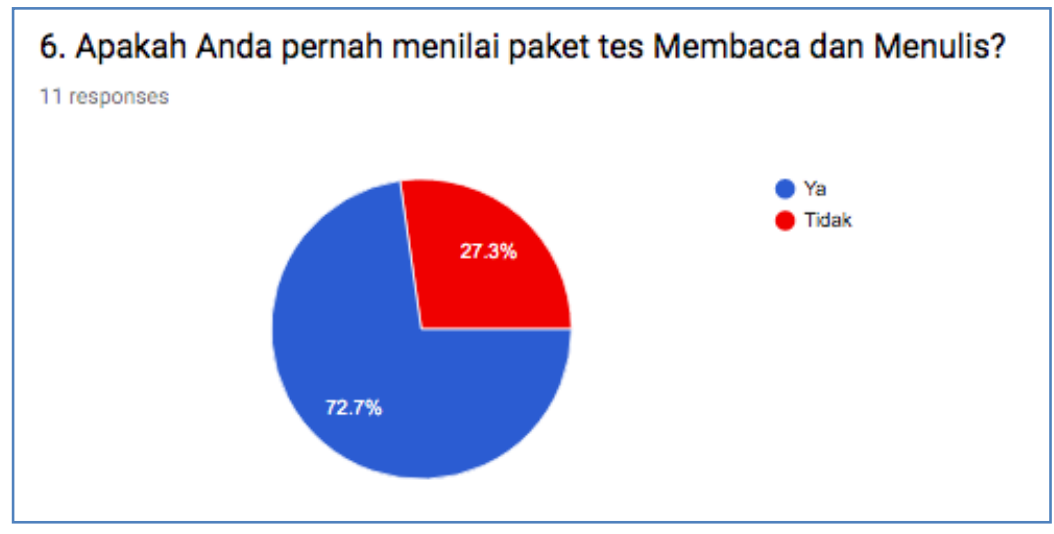

Berdasarkan hasil survei, hanya guru Bahasa Indonesia yang terlibat dalam menilai paket Tes Membaca dan Menulis, sedangkan guru bidang studi lain dan staf hanya terlibat dalam penilaian Tes Wicara.

Setelah melaksanakan survei untuk penilaian terhadap paket Tes Membaca dan Tes Menulis, survei dilanjutkan dengan pertanyaan tentang indikator dalam Tes Membaca dan Tes Menulis. Berikut adalah grafik yang menunjukkan hasil survei tersebut. 
GRAFIK 5. Grafik Hasil Survei tentang Indikator dalam Paket Tes Membaca dan Tes Menulis

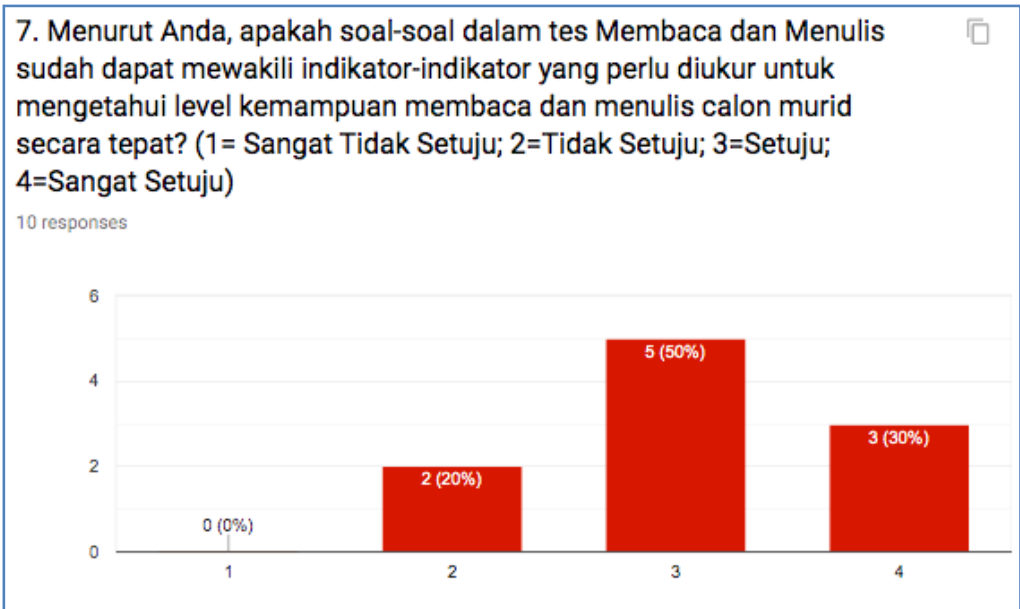

Berdasarkan hasil survei yang ditunjukkan pada grafik 5, 80\% responden setuju bahwa Tes Membaca dan Menulis sudah dapat mewakili indikator-indikator yang perlu diukur untuk menempatkan calon murid pada fase yang tepat, tetapi dua dari sepuluh responden tidak setuju. Dua responden tersebut adalah guru Bahasa Indonesia.

Di samping itu, penulis juga melakukan survei untuk mengetahui kejelasan Tes Membaca dan Menulis sebagai salah satu alat yang jelas untuk menentukan fase belajar bahasa Indonesia. Berikut adalah grafik yang menunjukkan hasil survei tersebut.

GRAFIK 6. Grafik Hasil Survei tentang Kejelasan

Paket Tes Membaca dan Tes Menulis sebagai Instrumen Tes Penempatan

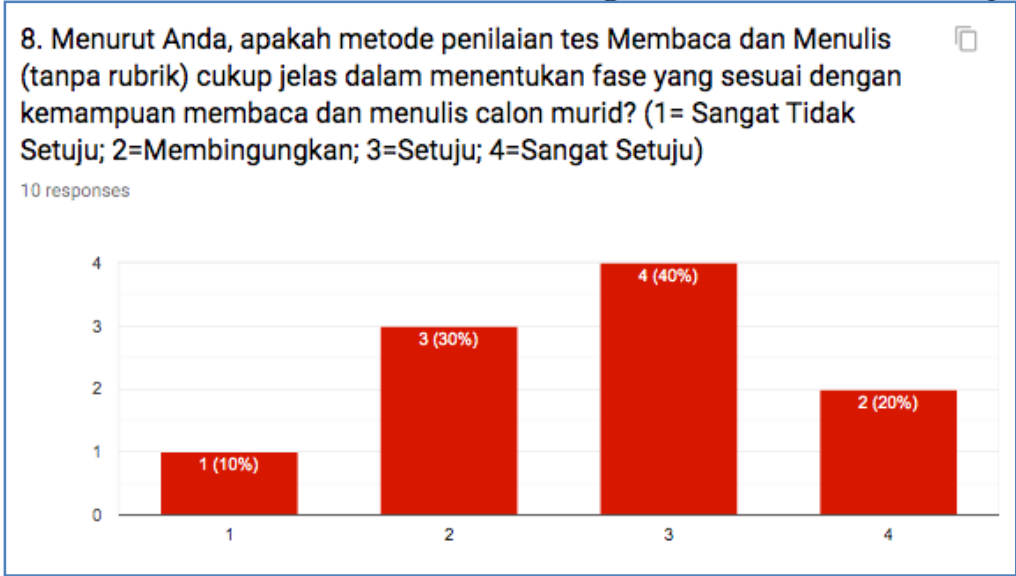

Berdasarkan survei, didapatkan hasil bahwa opini responden cukup terbagi ketika menilai apakah metode penilaian Tes Membaca dan Menulis tanpa rubrik dapat menentukan fase yang sesuai bagi murid. Empat puluh persen dari responden menyatakan bahwa penilaian tanpa rubrik membingungkan, sedangkan $60 \%$ menyatakan cukup jelas.

Setelah melakukan survei secara spesifik untuk Tes Wicara serta Tes Membaca dan Menulis, penulis melakukan survei secara menyeluruh terhadap instrument Tes Penempatan Bahasa Indonesia. Survei pertama dilakukan untuk memperoleh informasi tentang kejelasan instrumen tes dalam mengidentifikasi fase belajar bahasa Indonesia 
AKSIS: Jurnal Pendidikan Bahasa dan Sastra Indonesia Volume 3 Nomor 2, Desember 2019
e-ISSN: 2580-9040

e-Jurnal: http://doi.org/10.21009/AKSIS

siswa secara spesifik. Berikut adalah grafik yang menunjukkan hasil survei tersebut.

GRAFIK 7. Grafik Hasil Survei tentang Kejelasan

Paket Tes Membaca dan Tes Menulis sebagai Instrumen Tes Penempatan

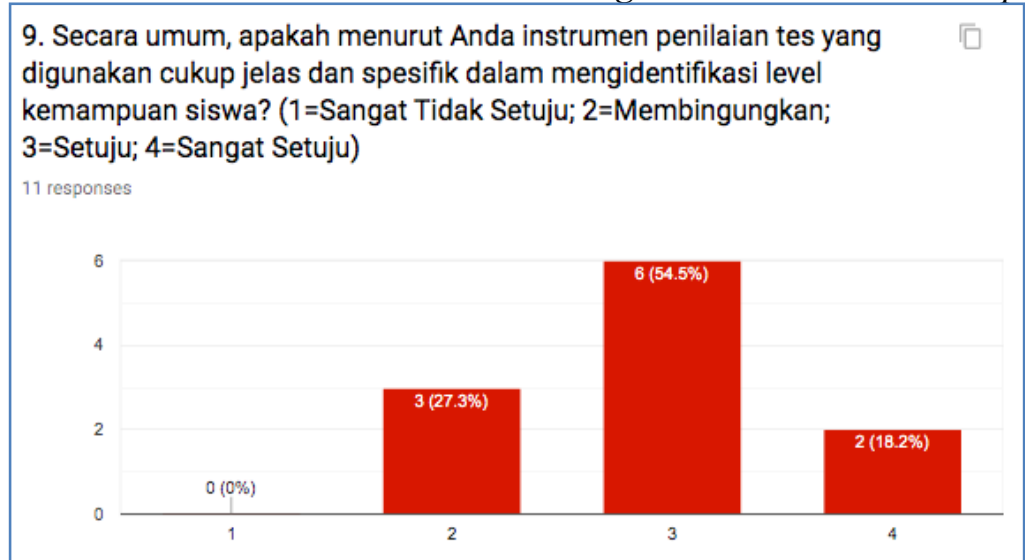

Berdasarkan hasil survei, tampak bahwa $72,7 \%$ dari responden menganggap instrumen penilaian tes yang dipakai saat ini cukup jelas, sedangkan 27,3\% responden menganggap bahwa instrumen masih membingungkan dalam menentukan fase siswa.

Kemudian, penulis juga melakukan survei tentang opini responden terhadap instrumen dan metode penilaian pada paket Tes Penempatan Bahasa Indonesia. Hasil survei disajikan pada grafik berikut.

GRAFIK 8. Grafik Hasil Survei tentang Kejelasan Instrumen dan Metode Penilaian pada Paket Tes Penempatan Bahasa Indonesia

10. Menurut Anda, apakah instrumen dan metode penilaian cukup
spesifik sehingga dua penilai yang berbeda akan dapat menyimpulkan
fase yang sama ketika menilai seorang calon siswa?
11 responses

Berdasarkan grafik 8, hasil survei menunjukkan bahwa 63,6\% responden tidak memiliki keyakinan bahwa instrumen dan metode penilaian cukup spesifik untuk dapat memberikan hasil yang konsisten tanpa tergantung dari siapa yang menilai. Responden selebihnya terbagi rata antara spesifik dan tidak spesifik.

Penulis pun melaksanakan survei terkait akurasi paket Tes Penempatan Bahasa Indonesia sebagai instrumen yang dapat menentukan fase belajar bahasa Indonesia siswa secara tepat. Hasil survei tersebut disajikan dalam grafik berikut. 
GRAFIK 9. Grafik Hasil Survei tentang Akurasi Penilaian Paket Tes Penempatan Bahasa Indonesia

11. Dari pengalaman Anda sebagai guru kelas Bahasa Indonesia,
apakah hasil penempatan murid baru berdasarkan tes kolektif ini sudah
akurat?
11 responses

Pada survei tersebut, ditemukan kerancuan dalam desain pertanyaan survei sehingga grafik tersebut tidak dapat dipakai untuk memberi data. Namun, hasil survei menunjukkan bahwa $75 \%$ dari guru Bahasa Indoonesia berpendapat bahwa hasil penempatan murid baru berdasarkan tes kolektif sudah akurat, sedangkan $25 \%$ berpendapat bahwa hasil penempatan belum akurat.

Selain melaksanakan survei terkait akurasi paket Tes Penempatan Bahasa Indonesia sebagai instrumen yang dapat menentukan fase belajar bahasa Indonesia siswa, penulis juga melaksanakan survei untuk menyaring masukan responden terkait faktor-faktor yang menyebabkan paket tes tersebut kurang akurat. Hasil survei dinyatakan dalam gambar berikut.

GAMBAR 1. Hasil Survei Faktor Penyebab Kurangnya Akurasi Paket Tes

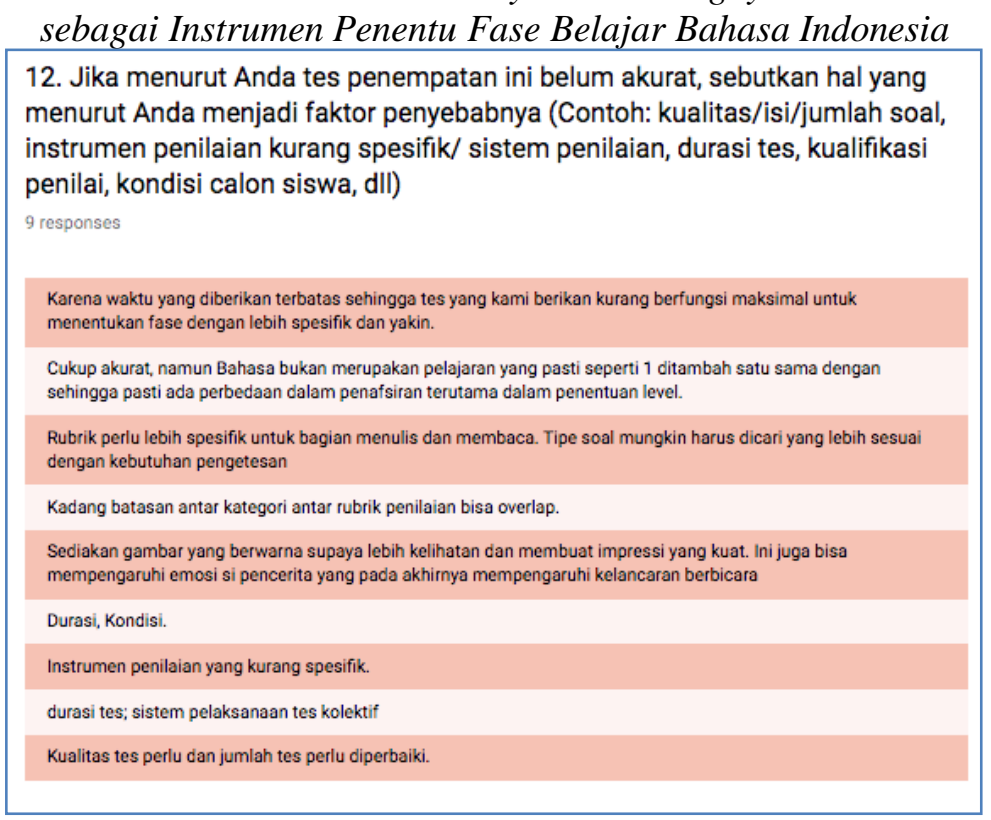

Berdasarkan survei, didapatkan hasil sebagai berikut. Responden yang berpendapat bahwa hasil tes masih tidak akurat menyebutkan bahwa hal ini dapat dipengaruhi oleh waktu/durasi tes yang kurang panjang, rubrik yang kurang spesifik, perlunya perbaikan dalam kualitas tes khususnya tipe dan jumlah soal, serta kondisi dan 
sistem pelaksanaan tes.

Selanjutnya, penulis juga melakukan survei kepada responden untuk mendapatkan saran dan masukan agar paket Tes Penempatan Bahasa Indonesia dapat menjadi paket tes yang akurat. Hasil survei dinyatakan dalam gambar berikut.

GAMBAR 2. Hasil Survei Saran dan Masukan terkait Akurasi Paket Tes sebagai Instrumen Penentu Fase Belajar Bahasa Indonesia

\begin{tabular}{l} 
13. Jika menurut Anda tes penempatan ini sudah cukup akurat, apakah Anda \\
mempunyai masukan/ide untuk membuatnya menjadi semakin baik? \\
9 responses \\
Materi tes harus diperbaharui supaya menarik, dan siswa lebih niat mengerjakannya. \\
Akan lebih bailk didaalm kertas diberi panduan agar pewawancara mengajukan beberapa pertanyaan sehari-hari \\
karena yang diwawancarai anak- anak yang akan merasa cemas di lingkungan baru. \\
$\begin{array}{l}\text { Penilai soal penempatan perlu adanya briefing sebelum melakukan penilaian essay supaya ada kesamaan } \\
\text { standar dalam penilaian sekaligus untuk membicarakan standar penilaian yang ciharapkan }\end{array}$ \\
Buat test membaca dan memahami artikel. Calon siswa membaca, kemudian pewawancara menanyakan 1 \\
pernyataan ttg konten artikel. \\
Dalam sesi wawancara, sepertinya minta juga murid menceritakan pengalaman yang mereka sukai untuk \\
melihat kelancaran berbicara. Kadangkala, karena tidak familiar dengan konteks gambar, jadi vocabularynya \\
juga terbatas dan ini mempengaruhi fluency. \\
Keadaan anak-anak yang test tidak di saat jadwal usM sebaiknya dperiksa kemballi kondisi ujiannya. \\
\hline Belum akurat \\
\hline kurangnya waktu yang diberikan kepada guru Bahasa Indonesia untuk menilai hasil tes; rubrik penilaian tes \\
kolektif membaca dan menulis perlu dibuat. \\
\hline rubrik masih kurang mewakili hasil, perlu diperbaiki sehingga rubrik merepresentasikan kemampuan anak.
\end{tabular}

Saran dan masukan yang dihimpun dari survei tersebut cukup beragam dan terinci. Oleh karena itu, hasil survei terkait saran dan masukan tersebut diuraikan dalam poin-poin berikut.

- Materi dibuat lebih menarik. Materi untuk Tes Wicara dapat ditambahkan artikel untuk memperjelas konteks gambar. Selain itu, tes dapat diganti dengan aktivitas menceritakan pengalaman yang disukai atau hal-hal yang familiar untuk anak-anak.

- Rubrik penilaian Tes Kolektif Membaca dan Menulis harus dibuat ulang melalui perbaikan rubrik yang sudah ada sehingga deskriptor penilaian pada rubrik benarbenar merepresentasikan kemampuan anak.

- Pihak-pihak yang menjadi penilai tes perlu diberikan pengarahan terkait penyamaan standar penilaian. Selain itu, penilai sebaiknya diberikan waktu yang cukup untuk menilai hasil tes.

- Pihak yang menjadi penilai untuk Tes Wicara, dengan kata lain menjadi pewawancara, hendaknya diberi panduan untuk mengajukan pertanyaan. Pertanyaan pun sebaiknya berhubungan dengan kehidupan sehari-hari sehingga membantu anak menjadi lebih komunikatif dalam berbicara meskipun berada pada lingkungan baru.

\section{Wawancara}

Selain melalui survei, pengumpulan data terkait analisis kebutuhan terhadap pengembangan paket Tes Penempatan Bahasa Indonesia juga dilaksanakan melalui kegiatan wawancara. Wawancara dilakukan kepada tiga responden sejak 15 November 2019 hingga 18 November 2019 dan dapat disimpulkan sebagai berikut. 
- Penempatan siswa di level yang tepat dalam sekolah ini adalah penting untuk memenuhi standar Language Acquisition sebanyak enam fase dan Language \& Literature dalam program IB.

- Materi tes kolektif masih belum sempurna dan belum dikembangkan, mengingat adanya kesalahan penempatan siswa setiap tahun. Dalam dua tahun terakhir terindikasi bahwa keakuratan hasil tes menurun.

- Tes dapat dijalankan tetapi masih belum efektif/ideal. Dalam wawancara tersebut ditemukan perbedaan pendapat antara guru Bahasa Indonesia dengan Staf Bidang Penerimaan. Staf Bidang Penerimaan diberi keleluasaan untuk menarik siswa di tengah-tengah tes tertulis untuk melakukan Tes Wicara dengan tujuan untuk mempersingkat waktu. Tes yang terlalu lama dianggap akan mempengaruhi performa siswa. Namun, ada kekhawatiran bahwa memotong waktu siswa di tengah-tengah tes menulis untuk wawancara dapat mengganggu konsentrasi siswa.

- Peneliti menyimpulkan bahwa desain dari soal yang meliputi tipe soal, durasi dan alokasi waktu per soal serta bagian, dan jenis soal harus dibuat sedemikian rupa sehingga dapat mendukung siswa untuk memberikan performa yang terbaik dalam waktu yang dibatasi.

- Ketika tes penempatan bahasa Indonesia dibuat, prioritas lebih diberikan untuk TesWicara. Guru diasumsikan menilai Tes Membaca dan Menulis dengan menggunakan rubrik IB, tetapi tidak ada dokumentasi bahwa hal ini diikuti oleh guru.

- Adanya ketidakkonsistenan hasil dan prosedur yang mungkin disebabkan oleh kurangnya koordinasi antara Departemen Bahasa Indonesia, bidang Penerimaan, dan Tata Usaha mengenai teknis pelaksanaan tes dan penilaian. Contohnya adalah kasus di mana hasil tes murid tidak pernah dinilai dan tes siswa yang langsung diberikan kepada TU tanpa diberikan kepada guru Bahasa Indonesia. Dengan kata lain, peneliti menyimpulkan bahwa Standar Operating Procedure belum ada atau belum tersosialisasi dengan baik.

- Keakuratan penempatan siswa dipengaruhi oleh berbagai faktor, yaitu kondisi psikis siswa (misalnya keseriusan dalam mengerjakan), prosedur dan standar penilaian (ada moderasi atau tidak), guru yang menilai, dan materi soal itu sendiri.

- Perlunya rubrik yang detil dan spesifik untuk Tes Wicara maupun Tes Membaca dan Menulis sesuai dengan standar MYP. Rubrik harus dibuat lebih spesifik untuk fase Language A dan setiap fase Language $B$ dari segi apa yang ingin dilihat, antara lain struktur kalimat, variasi kosakata, keruntutan ide, kompleksitas dalam menulis esai, dan lain-lain.

- Untuk Tes Menulis dan Membaca, disarankan untuk lebih memasukkan elemen struktur bahasa, imbuhan, pembuatan kalimat, dan lain-lain untuk menjawab kebutuhan murid non-Indonesia maupun siswa yang datang dari sekolah SPK. Tes Menulis dan Membaca saat ini sangat menitikberatkan pada pemahaman bacaan dan cara mengeluarkan pendapat di mana titik berat tersebut lebih cocok untuk anak dari sekolah nasional pada jenjang atas.

- Tes Menulis dan Tes Membaca dapat juga dibuat dalam beberapa bagian sehingga penilaian dapat dibagi antara guru Bahasa Indonesia dan guru lainnya atau staf. Contoh: Bagian A memiliki jawaban pasti sehingga dapat diperiksa oleh guru lain atau staf, sedangkan bagian $\mathrm{B}$ adalah esai sehingga harus diperiksa oleh guru Bahasa Indonesia. 
- Terdapat kesenjangan standar bahasa dalam sekolah tersebut, khususnya antara jenjang SD dan SMP yang belum terselesaikan hingga saat ini. Akibatnya, murid fase Language $A$ di jenjang SD tidak memenuhi standar untuk masuk fase Language A di SMP.

\section{Dokumentasi}

Berikut adalah daftar sampel guru serta perbandingan hasil tes penempatan siswa dengan fase terkini.

TABEL 1. Dokumentasi Jadwal Pelaksanaan Wawancara Guru (Inisial Nama)

\begin{tabular}{lcc}
\hline & Grade 7-10 \\
\hline Senin & YY & $11.25-12.15$ \\
\hline Selasa & LS & $11.30-12.15$ \\
\hline Rabu & IL & $11.45-12.30$ \\
\hline Kamis & MS & $10.30-11.20$ \\
\hline Jumat & SU & $11.25-12.15$ \\
\hline
\end{tabular}

TABEL 2. Perbandingan Hasil Tes Penempatan Siswa dengan Fase Terkini (Setelah Penyesuaian)

\begin{tabular}{|c|c|c|c|c|c|c|}
\hline Kelas & $\begin{array}{l}\text { Nama } \\
\text { Murid } \\
\text { (inisial) }\end{array}$ & $\begin{array}{l}\text { Hasil Tes } \\
\text { Membaca/ } \\
\text { Menulis }\end{array}$ & $\begin{array}{l}\text { Hasil Tes } \\
\text { Wicara }\end{array}$ & $\begin{array}{c}\text { Penempatan } \\
\text { Fase di Awal } \\
\text { Tahun } \\
\text { Akademik }\end{array}$ & $\begin{array}{l}\text { Penempatan } \\
\text { Fase Saat Ini }\end{array}$ & $\begin{array}{c}\text { Ada } \\
\text { Perbedaan } \\
\text { Antara Hasil } \\
\text { Tes dan Fase } \\
\text { Saat Ini }(\sqrt{ }) \\
\end{array}$ \\
\hline 7 & $\mathrm{CT}$ & 0 & Lang A & Lang A & Fase6 & $\sqrt{ }$ \\
\hline 7 & $\mathrm{JL}$ & 0 & Fase 5 & Fase 5 & Fase5 & \\
\hline 7 & DS & 0 & Fase 3 & Fase 4 & Fase4 & \\
\hline 7 & JT & 0 & Lang A & Lang A & Lang A & \\
\hline 7 & MW & 0 & Lang A & Lang A & Fase 5 & $\sqrt{ }$ \\
\hline 7 & JT & 0 & Lang A & Lang A & Lang A & \\
\hline 7 & MS & 0 & Lang A & Lang A & Lang A & \\
\hline 7 & $\mathrm{CW}$ & 0 & Lang A & Lang A & Fase 5 & $\sqrt{ }$ \\
\hline 7 & $\mathrm{VH}$ & $\mathrm{N} / \mathrm{A}$ & Lang A & Lang A & Lang A & \\
\hline 7 & $\mathrm{KH}$ & 0 & Fase 2 & Fase 2 & Fase 2 & \\
\hline 7 & $\mathrm{AK}$ & 0 & Lang A & Lang A & Fase 5 & $\sqrt{ }$ \\
\hline 7 & $\mathrm{CS}$ & 0 & Lang A & Lang A & Lang A & \\
\hline 7 & MK & 0 & Lang A & Lang A & Lang A & \\
\hline 7 & $\mathrm{JJ}$ & Lang A & $\mathrm{N} / \mathrm{A}$ & Lang A & Fase 5 & $\sqrt{ }$ \\
\hline 7 & JS & Lang B & Fase 2 & Fase 2 & Fase 2 & \\
\hline 7 & SP & N/A & Fase 2 & Fase 2 & Fase 2 & \\
\hline 7 & $\mathrm{JN}$ & 0 & Lang A & Lang A & Lang A & \\
\hline 8 & ST & 0 & Fase 4 & Lang A & Lang A & \\
\hline 8 & $\mathrm{BB}$ & 0 & Lang A & Lang A & Fase 4 & $\sqrt{ }$ \\
\hline 8 & AR & 0 & N/A & Lang A & Lang A & \\
\hline
\end{tabular}

\section{Keterangan:}

$\mathrm{N} / \mathrm{A}=$ tidak mengikuti tes

$0=$ mengikuti tes tetapi nilai tidak ditemukan

Berdasarkan data yang dihimpun dari tabel 2, terdapat tujuh pilihan penempatan bahasa Indonesia mulai dari pemula hingga yang paling tinggi, yaitu Lang $B$ yang terdiri atas fase 1 sampai fase 6 dan Lang $A$ yang merupakan tingkat paling tinggi. Dari dua 
puluh siswa baru kelas 7 dan 8 yang mendaftar, ditemukan setidaknya enam siswa atau $30 \%$ dari jumlah populasi pada penempatan fase yang tidak sesuai dengan hasil tes.

\section{KESIMPULAN}

Analisis kebutuhan yang dilakukan oleh peneliti di sekolah $\mathrm{X}$ memberikan sebuah penemuan bahwa pengembangan tes penempatan siswa hanyalah salah satu faktor dari banyak faktor yang dapat memengaruhi keakuratan penempatan siswa. Meskipun demikian, tes penempatan siswa adalah sebuah faktor yang signifikan dalam meningkatkan keakuratan penempatan siswa, mengingat mayoritas siswa baru harus melalui tes bahasa Indonesia.

Dari data yang didapat peneliti melalui observasi, wawancara, survei, dan dokumentasi, penulis mendapatkan kesimpulan bahwa ada kebutuhan pengembangan tes penempatan siswa dari segi materi soal, isi, kelengkapan rubrik, dan prosedur dalam melakukan penilaian.

Penelitian ini adalah sebuah penelitian pendahuluan dan akan digunakan untuk memulai tesis penelitian pengembangan tes penempatan bahasa Indonesia sesuai dengan kebutuhan di sekolah X.

\section{UCAPAN TERIMA KASIH}

Peneliti menyampaikan ucapan terima kasih kepada semua guru, staf Departemen Penerimaan, dan staf Tata Usaha di sekolah tempat penelitian ini dilakukan, terutama atas pemberian izin dari pimpinan untuk mengobservasi, mewawancarai, dan mengambil data. Peneliti juga mengucapkan terima kasih kepada tim redaksi Jurnal AKSIS atas saran dan masukan dalam penulisan jurnal ini.

\section{REFERENSI}

Ahmad, Z. (2017). Empowering EFL learners through a needs-based academic writing course design. International Journal of English Language Teaching, 5(9), 59 82.

Brown, J.D. (1995). The Elements of Language Curriculum: A Systematic Approach to Program Development. Boston: Heinle\&Heinle.

McCawley, P. (2004). Methods for Conducting an Educational Needs Assessment. Idaho: University of Idaho.

McKay, P. (2006). Assessing Young Language Learners. London: Cambridge University Press.

Sudaryanto, Soeparno \& Ferawati, L. (2019). Politics Of Language in Indonesia (19752015): Study Of History And Language Policy. Aksis: Jurnal Pendidikan Bahasa dan Sastra Indonesia 3(1). 129-139. doi: doi.org/10.21009/AKSIS.030113 